\title{
Global Diagnosis \\ A New Vision of Dental Diagnosis and Treatment Planning
}

Authors: J. William Robbins / Jeffrey S. Rouse

Publisher: Quintessence Publishing

Language: English

ISBN: 978-0-86715-523-5

Edition: $1 / \mathrm{e}$

Publish Year: 2016

Pages: 244, illustrated

Price: $148.00 €$

The authors of this book have developed a new vision on dental diagnosis and the treatment plan in their book called "Global Diagnosis". The book tries to provide clear and well-illustrated answers to the following five CORE questions: 1. What are the facial proportions and skeletal relationships? 2. What are the length and mobility of the upper lip? 3 What is the relationship between the gingival line and the horizon? 4. What is the length of the maxillary central incisor? 5 . Is the CEJ palpable in the gingival sulcus? The book has thirteen chapters and highlights how these five questions are used to determine the diagnosis and treatment option for various cases including crown lengthening, tissue grafting, intrusion, forced eruption, orthognathic surgery, dental facial plastics and extrusion. The final chapter provides the treatment planning template based on the CORE questions and encourages the readers to plan the treatment for these five case studies.

The book includes a CD and a lot of illustrations which help the clinician to establish a global diagnosis for the most difficult cases treatments.

DOI: 10.25241/stomaeduj.2017.4(3).bookreview.2

Marian-Vladimir Constantinescu

$\mathrm{DDS}, \mathrm{PhD}$ Holistic Dental \& Medical Institute of Bucharest-ROPOSTURO, Bucharest,

Romania
e-mail: dr.vladimir.constantinescu@gmail.com 